\section{Use of Commercially Available Heparin Solution for Neonates}

Arterial lines are commonly used to allow access for monitoring of neonates in neonatal intensive care units. Catheter occlusion and thrombosis are complications associated with the use of umbilical artery catheters, one type of arterial line used in this setting. The incidence of clinically symptomatic thrombosis with this type of catheter has been estimated at $1 \%$ to $3 \% .{ }^{1}$ To minimize these complications, staff in neonatal intensive care units use various strategies, including choice of catheter design, material, and location of the catheter tip. ${ }^{1,2}$ In most neonatal intensive care units, some type of heparin infusion is also used to help maintain patency of the catheter. ${ }^{2}$

The frequency of catheter occlusion is reduced when heparin is infused through the umbilical artery catheter. ${ }^{2}$ A continuous infusion of heparin is required, as heparinization of the flush solution is ineffective on its own. ${ }^{2}$ The exact amount of heparin required to maintain patency and avoid adverse effects is unknown. However, care is required in selecting the dosage, because heparin is a high-risk medication that carries a risk of hemorrhage if too much is administered.

Recently reported medication incidents have illustrated this risk. For example, in the neonatal intensive care unit of a Texas hospital, 14 to 17 neonates received heparin overdoses in the summer of $2008 .{ }^{3}$ No ready-to-administer solutions appropriate for neonates were commercially available at the time, ${ }^{3}$ so the required heparin solutions had to be prepared in the pharmacy. However, pharmacy staff prepared the heparin solutions incorrectly, and the neonates received up to 100 times more heparin than had been ordered. ${ }^{3}$ In Canada, a premixed heparin solution, at a concentration of 2 units $/ \mathrm{mL}$ in $0.9 \%$ sodium chloride, is commercially available. ${ }^{4}$ Whenever possible, using commercially available premixed solutions is preferable to the preparation of solutions by nurses or pharmacists to reduce the risk of mixing errors. However, the concentration of 2 units $/ \mathrm{mL}$ is greater than the 0.25 to $1 \mathrm{unit} / \mathrm{mL}$ recommended for neonates by the American College of Chest Physicians. ${ }^{1}$ Therefore, at many Canadian sites, the premixed solution is not used, and heparin for neonates (at the recommended concentration) is prepared in $0.45 \%$ sodium chloride. ${ }^{5}$

At a hospital in British Columbia, the charts of neonates who received commercially available heparin 2 units/mL in $0.9 \%$ sodium chloride from 2006 to 2009 were reviewed. During the study period, 66 neonates received heparin via an umbilical artery catheter. The mean gestational age of the patients was 27.3 weeks (range 24 to 40 weeks), and the mean birth weight was $1040 \mathrm{~g}$ (range 460 to $4075 \mathrm{~g}$ ). Sixty of the neonates initially received the commercially available solution, and the other 6 initially received a solution prepared on the ward, using $0.45 \%$ sodium chloride, but were switched to the commercially available solution at some point. The catheters were removed electively for $54(82 \%)$ of the neonates. Of the remaining 12 neonates whose umbilical artery catheters were removed because of complications, 7 (11\% of the total sample) of these removals were due to occlusion. This occlusion rate is similar to rates of about $13 \%$ reported from a few small randomized studies. ${ }^{6-8}$ Studies evaluating the recommended heparin concentrations of 0.25 to $1 \mathrm{unit} / \mathrm{mL}$ have reported variations in the dose of heparin from 25 to 220 units/kg daily. ${ }^{6-9}$ In the review reported here, the mean heparin dose was 29.3 units/kg daily (range 7.2 to 55 units $/ \mathrm{kg}$ daily).

One concern identified in this review was the need to switch from the commercially available solution $(0.9 \% \mathrm{NaCl})$ to the $0.45 \% \mathrm{NaCl}$ solution, because of hypernatremia, for $23(35 \%)$ of the neonates; as such, a total of $29(44 \%)$ of the neonates received the ward-mixed solution at some point. In particular, of the 58 very-low-birth-weight neonates (weighing less than $1500 \mathrm{~g}$ ), $28(48 \%)$ required the reduced-sodium solution. Administering exogenous sodium during early postnatal adaptation can prevent postnatal diuresis and may contribute to hypernatremia. ${ }^{10}$ Development of hypernatremia and subsequent administration of fluids may increase the risk of prolonged respiratory distress syndrome, patent ductus arteriosus, and bronchopulmonary dysplasia. ${ }^{10}$ In addition, hypernatremia and significant changes in sodium concentration may cause significant morbidity, including intraventricular hemorrhage and impairment of functional outcomes. ${ }^{11-13}$ The sodium in medications is often not considered as a contributing source, but use of $0.9 \%$ sodium chloride in an arterial line can deliver a substantial amount of sodium.

Given the morbidities associated with hypernatremia and large changes in serum sodium, the contributions of all exogenous sources of sodium must be carefully considered. Almost half of the neonates in this review required heparin in a reduced-sodium solution. Therefore, commercially available heparin ( 2 units $/ \mathrm{mL}$ in $0.9 \%$ sodium chloride) should not be administered routinely to very-low-birth-weight neonates (i.e., less than $1500 \mathrm{~g}$ ) without further studies. The US Institute for Safe Medication Practices recently suggested that the standard concentration of heparin for neonates be 0.5 units $/ \mathrm{mL}$ in $0.45 \%$ sodium chloride. ${ }^{14}$ Given this recommendation, perhaps the manufacturer will consider preparing a ready-to-administer product suitable for neonates.

\section{References}

1. Monagle P, Chalmers E, Chan A, DeVeber G, Kirkham F, Massicotte P, et al.; American College of Chest Physicians. Antithrombotic therapy in neonates and children: American College of Chest Physicians evidencebased clinical practice guidelines (8th edition). Chest 2008;133(6 Suppl):887S-968S.

2. Barrington KJ. Umbilical artery catheters in the newborn: effects of heparin. Cochrane Database Syst Rev 1999;(1):CD000507.

3. Heparin errors continue despite prior, high-profile, fatal events. ISMP Med Saf Alert 2008 Jul 17 [cited 2010 Nov 28]. Available from: www.ismp.org/newsletters/acutecare/articles/20080717.asp 
4. Heparin sodium in $.9 \%$ sodium chloride injection. In: Health Canada drug product database; 1994 Dec 31 [cited 2010 Nov 28]. Available from: http://webprod.hc-sc.gc.ca/dpd-bdpp/info.do?lang=eng\&code=10521

5. Newby B. Heparin for arterial lines in neonates. Message posted to Paediatrics-CSHPPSN@yahoogroups.com; 2010 Sep 7.

6. Ankola PA, Atakent YS. Effect of adding heparin in very low concentration to the infusate to prolong the patency of umbilical artery catheters. Am J Perinatol 1993;10(3):229-232.

7. Rajani K, Goetzman BW, Wennberg RP, Turner E, Abildgaard C. Effect of heparinization of fluids infused through an umbilical artery catheter on catheter patency and frequency of complications. Pediatrics 1979;63(4):552-556.

8. David RJ, Merten DF, Anderson JC, Gross S. Prevention of umbilical artery catheter clots with heparinized infusates. Dev Pharmacol Ther 1981;2(2):117-126.

9. Bosque E, Weaver L. Continuous versus intermittent heparin infusion of umbilical artery catheters in the newborn infant. J Pediatr 1986; 108(1):141-143.

10. Valentine CJ, Puthoff TD. Enhancing parenteral nutrition therapy for the neonate. Nutr Clin Pract 2007;22(2):183-193.

11. Lim WH, Lien R, Chiang MC, Fu RH, Lin JJ, Chu SM, et al. Hypernatremia and grade III/IV intraventricular hemorrhage among extremely low birth weight infants. J Perinatol 2010;31(3):193-198.

12. Baraton L, Ancel PY, Flamant C, Orsonneau JL. Darmaun D, Rozé JC. Impact of changes in serum sodium levels on 2-year neurologic outcomes for very preterm neonates. Pediatrics 2009;124(4):e655-e661.

13. Barnette AR, Myers BJ, Berg CS, Inder TE. Sodium intake and intraventricular hemorrhage in the preterm infant. Ann Neurol 2010; 67(6):817-823.

14. Standard concentrations of neonatal drug infusions. Horsham (PA): Institute for Safe Medication Practices and Vermont Oxford Network; 2011 [cited 2011 Jan 28]. Available from: www.ismp.org/Tools/ PediatricConcentrations.pdf

Brandi Newby, BSCPharm, ACPR

Clinical Pharmacy Specialist - Neonatal Intensive Care Unit

Surrey Memorial Hospital

Surrey, British Columbia clinical pharmacist had never been a member of the team. The only previous interactions that team members had had with pharmacists were brief communications with community practitioners regarding dispensing functions.

We used an approach known as action research, a qualitative methodology involving a cyclical, dynamic, and collaborative process in which researchers strive to improve their practices. We worked with established primary and ambulatory care pharmacists and members of the primary care team to define and tailor the activities of the proposed clinical pharmacist position. A pharmacist then joined the team and carried out the agreed-upon services. Focus groups were held with the team at the end of the study period to evaluate the pharmacist's role. The results of this process were ultimately used to create an 8-step guide for this integration process. This guide or template may be of interest to all clinical pharmacists who wish to become part of a primary health care team but who are unclear about what their roles or expectations should be.

\section{References}

1. Kolodziejak L, Rémillard A, Neubauer S. Integration of a primary healthcare pharmacist. J Interprof Care 2010;24(3):274-284.

\section{Lynette Kosar (formerly Kolodziejak), BSP, MSC \\ Department of Pharmacy Practice \\ Regina Qu'Appelle Health Region \\ Regina, Saskatchewan}

Alfred Rémillard, BSc(Pharm), PharmD, BCPP

Associate Dean of Research and Graduate Affairs

Professor of Pharmacy

College of Pharmacy and Nutrition

University of Saskatchewan

Regina, Saskatchewan

Dr Rémillard is also an Associate Member of the Department of Psychiatry in the College of Medicine at the University of Saskatchewan.

\section{Sharing Data from Pharmacy Information Systems}

In a recent issue of the $C J H P$, Brisseau and others ${ }^{1}$ discussed the topic of sharing data from pharmacy information systems to electronic health records. I was dismayed by some of the misleading and inaccurate information presented in this letter.

I would first take issue with the number that the authors quoted from the Hospital Pharmacy in Canada Survey, suggesting that " $6 \%$ of departments were using this type of medical record" [i.e., electronic health records]. ${ }^{1}$ I seriously doubt this number and could not find its source anywhere in the published survey. In fact, Table J-5 of the survey report ${ }^{2}$ states an $81 \%$ achievement rate among pharmacists in using medicationrelevant portions of patients' electronic medical records for managing patients' medication therapy. This rate of use necessarily implies that such electronic medical records actually exist. I suspect that the authors were confusing the rate of implementation of electronic health records with the rate of uptake of 